\title{
Prevalence and risk factors of anemia among pregnant women attending a high-volume tertiary care center for delivery
}

\author{
Cüneyt Eftal Taner ${ }^{1}$, Atalay Ekin ${ }^{1}$, Ulaş Solmaz', Cenk Gezer ${ }^{1}$, Birgül Çetin², Mustafa Keleşoğlu², \\ Merve Bayrak Erpala², Mehmet Özeren ${ }^{1}$ \\ ${ }^{1}$ Department of Obstetrics and Gynecology, Tepecik Training and Research Hospital, Izmir, Turkey \\ ${ }^{2}$ Department of Family Medicine, Tepecik Training and Research Hospital, İzmir, Turkey
}

\begin{abstract}
Objective: The aim of this study was to identify the prevalence of anemia and predisposing factors contributing to anemia in pregnant women prior to delivery.

Material and Methods: A retrospective case-control study was conducted on 1221 women who delivered between 37 and 42 weeks of gestation between July 2014 and January 2015. Data on the subjects' socioeconomic and demographic characteristics, pregnancy outcomes, and hemoglobin levels within $24 \mathrm{~h}$ prior to delivery were collected. The study population was divided into two groups on the basis of the presence of anemia within $24 \mathrm{~h}$ prior to delivery. Anemia was defined as a hemoglobin level of $<11 \mathrm{~g} / \mathrm{dL}$. The prevalence of pre-delivery anemia was estimated, and antenatal predictors of anemia were determined using multivariate logistic regression analysis.

Results: The prevalence of anemia in women attending our center for delivery was 41.6\% [95\% confidence interval (CI) $=38.84-44.37$ ] . After multivariate logistic regression analysis, parity $>3$ [odds ratio $(\mathrm{OR})=1.82,95 \% \mathrm{CI}=1.24-2.96, \mathrm{p}=0.002$ ], illiterate $(\mathrm{OR}=2.23,95 \% \mathrm{CI}=1.35-3.45$, $\mathrm{p}=0.001)$ and primary educational level $(\mathrm{OR}=2.01,95 \% \mathrm{CI}=1.28-3.39, \mathrm{p}=0.008)$, household monthly income per person $<250$ Turkish liras $(\mathrm{OR}=2.34,95 \% \mathrm{Cl}=1.49-3.89, \mathrm{p}<0.001)$, first admission at second $(\mathrm{OR}=1.63,95 \% \mathrm{Cl}=1.24-2.81, \mathrm{p}=0.006)$ and third trimester $(\mathrm{OR}=2.45,95 \%$ $\mathrm{CI}=1.41-4.06, \mathrm{p}<0.001)$, number of antenatal visits $<5(\mathrm{OR}=1.45,95 \% \mathrm{CI}=10.5-2.11)$ and $5-10(\mathrm{OR}=1.3,95 \% \mathrm{CI}=1.03-2.09)$, duration of iron supplementation $<3$ months $(\mathrm{OR}=2.62,95 \% \mathrm{CI}=1.51-4.17)$ and $3-6$ months $(\mathrm{OR}=1.68,95 \% \mathrm{CI}=1.13-2.91)$, and occurrence of preeclampsia $(\mathrm{OR}=1.55,95 \% \mathrm{Cl}=1.03-2.1, \mathrm{p}=0.041)$ were independently associated with anemia.

Conclusion: Socioeconomic determinants constitute most of the anemia cases and, hence, should be considered as major risk factors of anemia in women attending for delivery at term. (J Turk Ger Gynecol Assoc 2015; 16: 231-6)
\end{abstract}

Keywords: Anemia, delivery, perinatal outcome, pregnancy, socioeconomic factors

Received: 14 April, 2015

Accepted: 15 July, 2015

Available Online Date: 02 November, 2015

\section{Introduction}

Anemia in pregnancy is one of the most common preventable causes of maternal morbidity and poor perinatal outcome. The main causes of anemia during pregnancy involve deficiencies of key nutrients, infections, and parasitic diseases (1). Among these etiologic factors, iron deficiency is often identified as the primary contributor to anemia in pregnancy. In Turkey, routine iron supplementation to all pregnant women has been advised since 2005 (2). Despite the implementation of the program for a decade, anemia in pregnancy still remains as one of the major health problems in the country with a prevalence of $32.6 \%$ (3).

In developing countries, demographic, cultural, and socioeconomic factors could affect the occurrence of anemia in pregnancy. In addition, previous studies have found a significant association between maternal anemia and adverse peri- natal outcomes such as placenta previa, placental abruption, preterm birth, and low birth weight $(4,5)$. The determination of these factors will help to provide valuable information for the identification of the "at-risk" group and also for the implementation of interventions to reduce anemia. However, these studies regarding the etiology of anemia in pregnancy were conducted with anemic women prior to conception or during the first trimester of pregnancy $(4,5)$. There is a need for studies exploring the prevalence of anemia and predisposing risk factors for anemia observed at the time of delivery.

Pregnant women with anemia, those going into labor and delivery, have the highest potential to encounter complications related to anemia and transfusion (6-8). A modest blood loss at delivery may not impair the hemodynamic response of women with normal hemoglobin levels but may be too hazardous for anemic women $(5,7,9)$. In addition, there may not be enough time for clinicians to normalize the hemoglobin 
levels of delivering women, particularly in places where transfusion facilities are limited.

Consequently, in this study we aimed to determine the prevalence of anemia and identify the factors contributing to anemia in pregnant women attending our center for delivery at term.

\section{Material and Methods}

This study was conducted retrospectively with women who had delivered at a high-volume tertiary care center between July 2014 and January 2015. Our study was performed in accordance with the ethical standards laid down in the 1964 Declaration of Helsinki, and the research protocol was approved by the Ethics Committee of our center. Informed consent was obtained from all participants. The study population consisted of singleton pregnancies that delivered between 37 and 42 weeks of gestation and were monitored in the obstetric unit of our center after delivery. Chronic diseases leading to anemia such as renal, cardiac, and lung diseases and hemoglobinopathy were excluded. The minimum sample size required for this study was estimated by assuming a confidence interval of $95 \%$, a $5 \%$ margin of error, and a prevalence of $32.6 \%$ for anemia among pregnant women. Accordingly, the minimum sample size required for the study was 333 . A total of 1221 women were enrolled in the study, and all of them were recruited to increase the power of the study.

Before discharge, all the women who had delivered were interviewed using a questionnaire to collect their socioeconomic and demographic data. Furthermore, the following information was obtained from the computerized medical record system of our hospital: hemoglobin value within $24 \mathrm{~h}$ prior to delivery, maternal age, number of parity and abortus, body mass index before pregnancy, weight gain during pregnancy, educational level, occupational status, household monthly income per person, smoking habit, alcohol consumption, number of antenatal care visits, number of ultrasonography examinations done during pregnancy, gestational age at first admission, gestational age at delivery, and duration of iron and folic acid supplementation. Household monthly income per person was calculated as the total household monthly income divided by the total number of family members living together. Adverse perinatal outcomes were recorded as dichotomous variables (yes or no) and included antenatal bleeding, hypermesis gravidarum, placenta previa, gestational diabetes, preeclampsia, intrauterine growth restriction, and congenital anomalies. We categorized patients into two groups according to the presence or absence of anemia within $24 \mathrm{~h}$ before the onset of delivery. Anemia was defined as a hemoglobin level of $<11 \mathrm{~g} / \mathrm{dL}$ according to the World Health Organization criteria (3). The prevalence and antenatal predictors of anemia in pregnant women attending our center for delivery was determined.

According to our protocol, an oral dose of $30 \mathrm{mg} /$ day iron was prescribed to all non-anemic pregnant women, and if anemia was diagnosed, the iron dose was increased to $60-120 \mathrm{mg} /$ day until the anemia was treated. Similarly, periconceptional $0.4 \mathrm{mg}$ of folic acid supplementation was recommended for all women planning a pregnancy and those in their first trimester of gestation.
Statistical analyses were performed using Statistical Package for the Social Sciences (SPSS) for Windows version 20.0 (SPSS Inc., Chicago, Illinois, USA). Continuous and categorical data were expressed as mean \pm standard deviation and the number of patients, respectively. The means of the continuous variables were compared using t-test between the two groups after checking that the variables were normally distributed. The distribution of categorical variables was examined using chisquare statistics. Risk factors and perinatal outcomes associated with anemia were determined using multivariate logistic regression modeling with backward elimination. Odds ratio (OR) and their 95\% confidence intervals (CI) were calculated. $\mathrm{P}<0.05$ was considered statistically significant.

\section{Results}

A total of 1221 women attended our center for delivery during the study period, among which 508 (41.6\%, 95\% CI=38.8444.37) had a hemoglobin level $<11 \mathrm{~g} / \mathrm{dL}$ and 713 (58.4\%, 95\% $\mathrm{CI}=55.6-61.12)$ had a level of $\geq 11 \mathrm{~g} / \mathrm{dL}$. The socioeconomic and demographic characteristics for groups with normal and low hemoglobin level are shown in Table 1. Maternal age $>35$ years $(\mathrm{OR}=1.47,95 \% \mathrm{CI}=1.04-2.08, \mathrm{p}=0.029)$, body mass index $\geq 30(\mathrm{OR}=1.72,95 \% \mathrm{CI}=1.06-2.79, \mathrm{p}=0.027)$, parity $>3$ $(\mathrm{OR}=2.38,95 \% \mathrm{CI}=1.74-3.26, \mathrm{p}<0.001)$, illiterate $(\mathrm{OR}=2.09$, $95 \% \mathrm{CI}=1.31-3.35, \mathrm{p}=0.002)$ and primary educational level (OR=2.67, 95\% CI=1.90-3.74, p<0.001), absence of occupation $(\mathrm{OR}=1.48,95 \% \mathrm{CI}=1.06-2.09, \mathrm{p}=0.021)$, household monthly income per person $<250$ Turkish liras (TL) (OR=4.94, 95\% $\mathrm{CI}=3.37-7.25, \mathrm{p}<0.001)$ and $250-500 \mathrm{TL}(\mathrm{OR}=2.58,95 \%$ $\mathrm{CI}=1.81-3.68, \mathrm{p}<0.001$ ), weight gain during pregnancy $<10 \mathrm{~kg}$ $(\mathrm{OR}=1.56,95 \% \mathrm{CI}=1.09-2.24, \mathrm{p}=0.016)$, number of antenatal visits $<5(\mathrm{OR}=2.49,95 \% \mathrm{CI}=1.63-3.81, \mathrm{p}<0.001)$ and $5-10$ $(\mathrm{OR}=1.71,95 \% \mathrm{CI}=1.34-2.17, \mathrm{p}<0.001)$, admission to antenatal care at second $(\mathrm{OR}=1.90,95 \% \mathrm{CI}=1.45-2.49, \mathrm{p}<0.001)$ and third trimester of gestation $(\mathrm{OR}=1.93,95 \% \mathrm{CI}=1.44-2.58, \mathrm{p}<0.001)$, and duration of iron supplementation $<3$ months $(\mathrm{OR}=2.53$, $95 \% \mathrm{CI}=1.81-3.53, \mathrm{p}<0.001)$ and $<3-6$ months $(\mathrm{OR}=2.09$, $95 \% \mathrm{CI}=1.60-2.72, \mathrm{p}<0.001)$ were significantly associated with anemia at the time of delivery. The perinatal outcomes associated with anemia are presented in Table 2. Antenatal bleeding $(\mathrm{OR}=2.09,95 \% \mathrm{CI}=1.02-4.28, \mathrm{p}=0.039)$ and preeclampsia $(\mathrm{OR}=2.68,95 \% \mathrm{CI}=1.13-6.37, \mathrm{p}=0.02)$ were associated with an increased risk of anemia. There were no other significant differences between the groups in demographic characteristics and perinatal outcomes.

To further identify the predictors of anemia within $24 \mathrm{~h}$ before delivery, multiple logistic regression analysis was performed to control for potential confounders (Table 3). Among the risk factors, parity $>3(\mathrm{OR}=1.82,95 \% \mathrm{CI}=1.24-2.96, \mathrm{p}=0.002)$, illiterate $(\mathrm{OR}=2.23,95 \% \mathrm{CI}=1.35-3.45, \mathrm{p}=0.001)$ and primary educational level ( $\mathrm{OR}=2.01,95 \% \mathrm{CI}=1.28-3.39, \mathrm{p}=0.008)$, household monthly income per person $<250 \mathrm{TL}(\mathrm{OR}=2.34,95 \% \mathrm{CI}=1.49$ $3.89, \mathrm{p}<0.001)$, number of antenatal visits $<5(\mathrm{OR}=1.45,95 \%$ $\mathrm{CI}=10.5-2.11)$ and $5-10(\mathrm{OR}=1.3,95 \% \mathrm{CI}=1.03-2.09)$, admission to antenatal care at second $(\mathrm{OR}=1.63,95 \% \mathrm{CI}=1.24-$ $2.81, \mathrm{p}=0.006)$ or third trimester of gestation $(\mathrm{OR}=2.45,95 \%$ 
Table 1. Association between clinical characteristics and anemia in women attending our center for delivery

\begin{tabular}{|c|c|c|c|c|}
\hline & $\begin{array}{c}\mathrm{Hb}<11 \mathrm{~g} / \mathrm{dL} \\
\quad n(\%)\end{array}$ & $\begin{array}{c}\mathrm{Hb} \geq 11 \mathrm{~g} / \mathrm{dL} \\
n(\%)\end{array}$ & OR $(95 \% \mathrm{CI})$ & $\mathbf{p}$ \\
\hline \multicolumn{5}{|c|}{ Maternal age (y) } \\
\hline$<20$ & $42(40.8)$ & $61(59.2)$ & $1.05(0.69-0.61)$ & 0.823 \\
\hline $20-29$ & 239 & 365 & 1 & \\
\hline $30-34$ & $147(28.9)$ & $204(28.6)$ & $1.1(0.84-1.44)$ & 0.484 \\
\hline$>35$ & 80 & 83 & $1.47(1.04-2.08)$ & 0.029 \\
\hline \multicolumn{5}{|l|}{ BMI $\left(\mathrm{kg} / \mathrm{m}^{2}\right)$} \\
\hline$<18.5$ & $29(37.7)$ & $48(62.3)$ & $0.93(0.57-1.51)$ & 0.764 \\
\hline $18.5-24.9$ & $288(39.4)$ & $443(60.6)$ & 1 & \\
\hline $25-29.9$ & $153(44.9)$ & $188(55.1)$ & $1.25(0.96-1.62)$ & 0.09 \\
\hline$\geq 30$ & $38(52.8)$ & $34(47.2)$ & $1.72(1.06-2.79)$ & 0.027 \\
\hline \multicolumn{5}{|l|}{ Parity } \\
\hline 0 & 152 & 282 & 1 & \\
\hline $1-3$ & 211 & 318 & $1.23(0.95-1.60)$ & 0.121 \\
\hline$>3$ & 145 & 113 & $2.38(1.74-3.26)$ & $<0.001$ \\
\hline \multicolumn{5}{|l|}{ Abortion } \\
\hline 0 & 356 & 523 & 1 & \\
\hline $1-2$ & 142 & 176 & $1.18(0.91-1.53)$ & 0.198 \\
\hline$>2$ & 10 & 14 & $1.05(0.46-2.39)$ & 0.920 \\
\hline \multicolumn{5}{|c|}{ Educational level } \\
\hline Illiterate & 60 & 56 & $2.09(1.31-3.35)$ & 0.002 \\
\hline Primary & 255 & 348 & $2.67(1.90-3.74)$ & $<0.001$ \\
\hline Secondary & 127 & 180 & $1.38(0.95-2.0)$ & 0.091 \\
\hline Higher & 66 & 129 & 1 & \\
\hline \multicolumn{5}{|c|}{ Occupational status } \\
\hline No & 448 & 595 & $1.48(1.06-2.09)$ & 0.021 \\
\hline Yes & 60 & 118 & 1 & \\
\hline \multicolumn{5}{|c|}{ Household monthly income/person (TL) } \\
\hline 250 & 195 & 148 & $4.94(3.37-7.25)$ & $<0.001$ \\
\hline $250-500$ & 265 & 385 & $2.58(1.81-3.68)$ & $<0.001$ \\
\hline$>500$ & 48 & 180 & 1 & \\
\hline \multicolumn{5}{|c|}{ Weight gain $(\mathrm{kg})$} \\
\hline$<10$ & 71 & 65 & $1.56(1.09-2.24)$ & 0.016 \\
\hline $10-18$ & 357 & 510 & 1 & \\
\hline$>18$ & 80 & 138 & $0.83(0.61-1.13)$ & 0.228 \\
\hline \multicolumn{5}{|l|}{ Smoking } \\
\hline No & 488 & 697 & 1 & \\
\hline Yes & 20 & 16 & $0.56(0.29-1.09)$ & 0.085 \\
\hline \multicolumn{5}{|l|}{ Alcohol } \\
\hline No & 499 & 710 & 1 & \\
\hline Yes & 11 & 7 & $0.45(0.17-1.16)$ & 0.09 \\
\hline
\end{tabular}




\begin{tabular}{|c|c|c|c|c|}
\hline \multicolumn{5}{|l|}{ No. of admissions to antenatal care } \\
\hline$<5$ & 58 & 44 & $2.49(1.63-3.81)$ & $<0.001$ \\
\hline $5-10$ & 232 & 257 & $1.71(1.34-2.17)$ & $<0.001$ \\
\hline$>10$ & 218 & 412 & 1 & \\
\hline \multicolumn{5}{|l|}{ No. of USG } \\
\hline$<5$ & 41 & 76 & $0.72(0.48-1.09)$ & 0.109 \\
\hline $5-10$ & 295 & 392 & 1 & \\
\hline$>10$ & 172 & 245 & $0.93(0.73-1.19)$ & 0.583 \\
\hline \multicolumn{5}{|l|}{ Gestational age at first admission (days) } \\
\hline First trimester & 157 & 327 & 1 & \\
\hline Second trimester & 202 & 221 & $1.90(1.45-2.49)$ & $<0.001$ \\
\hline Third trimester & 151 & 163 & $1.93(1.44-2.58)$ & $<0.001$ \\
\hline Gestational age at delivery (weeks) & $38.2 \pm 2.18$ & $38.4 \pm 1.94$ & & \\
\hline \multicolumn{5}{|l|}{ Iron supplementation (months) } \\
\hline$<3$ & 116 & 109 & $2.53(1.81-3.53)$ & $<0.001$ \\
\hline $3-6$ & 264 & 300 & $2.09(1.60-2.72)$ & $<0.001$ \\
\hline$>6$ & 128 & 304 & 1 & \\
\hline \multicolumn{5}{|l|}{ Folic acid supplementation } \\
\hline None & 215 & 302 & $1.27(0.87-1.84)$ & 0.211 \\
\hline First trimester & 238 & 313 & $1.36(0.93-1.96)$ & 0.107 \\
\hline Periconceptional & 55 & 98 & 1 & \\
\hline \multicolumn{5}{|c|}{ BMI: body mass index; CI: confidence interval; Hb: hemoglobin; OR: odds ratio; TL: Turkish liras; USG: ultrasonography } \\
\hline
\end{tabular}

Table 2. Perinatal outcomes associated with anemia in women attending our center for delivery

\begin{tabular}{|l|c|c|c|c|}
\hline & $\begin{array}{c}\mathbf{H b}<\mathbf{1 1} \\
\mathbf{g} / \mathbf{d L} \\
\mathbf{n}\end{array}$ & $\begin{array}{c}\mathbf{H b} \geq \mathbf{1 1} \\
\mathbf{g} / \mathbf{d L} \\
\mathbf{n}\end{array}$ & $\begin{array}{c}\mathbf{O R} \\
\mathbf{( 9 5 \%} \mathbf{C I})\end{array}$ & $\mathbf{p}$ \\
\hline Antenatal bleeding & 19 & 13 & $2.09(1.02-4.28)$ & 0.039 \\
\hline Hyperemesis gravidarum & 11 & 14 & $1.10(0.50-2.45)$ & 0.806 \\
\hline Gestational diabetes & 12 & 15 & $1.13(0.52-2.43)$ & 0.764 \\
\hline Preeclampsia & 15 & 8 & $2.68(1.13-6.37)$ & 0.02 \\
\hline IUGR & 11 & 16 & $0.96(0.44-2.09)$ & 0.92 \\
\hline Placenta previa & 9 & 12 & $1.05(0.44-2.52)$ & 0.92 \\
\hline Congenital anomalies & 19 & 25 & $1.07(0.58-1.96)$ & 0.823 \\
\hline $\begin{array}{l}\text { Cl: confidence interval; Hb: hemoglobin; OR: odds ratio; IUGR: intrauterine } \\
\text { growth restriction }\end{array}$ & & \\
\hline
\end{tabular}

$\mathrm{CI}=1.41-4.06, \mathrm{p}<0.001)$, duration of iron supplementation $<3$ months (OR=2.62, 95\% $\mathrm{CI}=1.51-4.17)$ and 3-6 months ( $\mathrm{OR}=1.68,95 \% \mathrm{Cl}=1.13-2.91)$, and occurrence of preeclampsia $(\mathrm{OR}=1.55,95 \% \mathrm{CI}=1.03-2.1, \mathrm{p}=0.041)$ were independently associated with anemia.

\section{Discussion}

This study revealed that the prevalence of anemia in women within $24 \mathrm{~h}$ before delivery was $41.6 \%$, which is higher than the estimated average prevalence rate of $32.6 \%$ documented by World Health Organization (WHO) for our country (3). This high prevalence of anemia among pregnant women in this study may be explained by the distribution of socioeconomic status of the population. This estimation of WHO for Turkey was acquired from community-based surveys. However, the rate in our study was derived from the population, which was mainly composed of women with lower socioeconomic status. Another noteworthy point is the variation in the gestational age at the time of measurement. Contrary to previous studies, the hemoglobin values of the women in our study were evaluated in the third trimester of pregnancy, in which fetal growth and red blood cell expansion increases the prevalence of anemia $(4,5)$. Additionally, in this study, it is demonstrated that pre-delivery anemia was related to parity, educational level, household monthly income per person, number of hospital admissions, gestational age at the first admission, duration of iron supplementation, and preeclampsia.

Results in our study showed that pregnancies with parity more than 3 were 1.8 times more likely to have anemia than those with a parity $\leq 3$. Higher parity was documented in a number of studies as a cause of anemia in pregnancy $(10,11)$. In contrast, Ezugwu et al. (12) did not find any significant difference among nulliparous, multiparous, and grand multiparous groupings with respect to maternal anemia. However, low proportion of grand multiparous women (3.7\%) in their study participants might have pushed the contribution of parity to statistically insignificant levels. Possible explanation to the high prevalence of anemia among grand multiparous women is that these 
Table 3. Multivariate logistic regression analysis of risk factors and anemia

\begin{tabular}{|l|c|c|c|}
\hline & OR & $\mathbf{9 5 \%}$ CI & $\mathbf{p}$ \\
\hline Maternal age $>35$ & 1.23 & $0.92-1.61$ & 0.223 \\
\hline $\mathrm{BMI} \geq 30\left(\mathrm{~kg} / \mathrm{m}^{2}\right)$ & 1.19 & $0.89-1.63$ & 0.102 \\
\hline Parity $>3$ & 1.82 & $1.24-2.96$ & 0.002 \\
\hline Unemployment & 1.20 & $0.89-1.57$ & 0.121 \\
\hline Educational level & \multicolumn{3}{|l}{} \\
\hline Illiterate & 2.23 & $1.35-3.45$ & 0.001 \\
\hline Primary & 2.01 & $1.28-3.39$ & 0.008 \\
\hline
\end{tabular}

Household monthly income/person (TL)

\begin{tabular}{|l|c|c|c|}
\hline$<250$ & 2.34 & $1.49-3.89$ & $<0.001$ \\
\hline $250-500$ & 1.74 & $0.98-3.51$ & 0.071 \\
\hline Weight gain<10 kg & 1.13 & $0.88-1.57$ & 0.145 \\
\hline
\end{tabular}

No. of admissions to antenatal care

\begin{tabular}{|l|l|l|l|}
\hline$<5$ & 1.45 & $1.05-2.11$ & 0.012 \\
\hline $5-10$ & 1.30 & $1.03-2.09$ & 0.028 \\
\hline
\end{tabular}

Gestational age at first admission

\begin{tabular}{|l|c|c|c|}
\hline Second trimester & 1.63 & $1.24-2.81$ & 0.006 \\
\hline Third trimester & 2.45 & $1.41-4.06$ & $<0.001$ \\
\hline
\end{tabular}

Iron supplementation (m)

\begin{tabular}{|l|c|c|c|}
\hline$<3$ & 2.62 & $1.51-4.17$ & $<0.001$ \\
\hline $3-6$ & 1.68 & $1.13-2.91$ & 0.001 \\
\hline Antenatal bleeding & 1.34 & $0.94-3.47$ & 0.212 \\
\hline Preeclampsia & 1.55 & $1.03-2.10$ & 0.041 \\
\hline
\end{tabular}

CI: confidence interval; OR: odds ratio; BMI: body mass index; TL: Turkish liras

women might have got pregnant with low levels of nutrients due to the depletion of reserves of the mother in prior pregnancies and lactation periods.

Women with low educational level and household monthly income per person were detected to be significantly more vulnerable to anemia than others. Confirming this observation, Ndukwu and Dienye (13) reported an inverse relationship between the prevalence of anemia and socioeconomic status. In addition, the severity of anemia was also found to be inversely related to educational status and family income (14). This is not surprising considering the fact that women who were poorly educated and had financial constraints might suffer the deleterious effects of poor nutrition and not have early access to health services.

Women who were taking iron supplements for less than 3 months and 3-6 months had 2.62 and 1.68 times the risk of anemia at term, respectively. Similar observations were made in several studies that documented a reduction in the prevalence of anemia at the end of pregnancy after routine supplementation of iron to pregnant women $(15,16)$. On the other hand, a study from the United States did not demonstrate any effect of prenatal prophylactic iron supplementation on the overall prevalence of anemia (17). The possible reason why an association was not observed in the previous study is that they carried out the study with patients who had adequate iron stores. In addition, the power of that study was affected due to the lack of follow up (17). Therefore, for anemia intervention to be most effective, it is important that women should attend antenatal clinics in the first trimester of their pregnancies. In this study, only $17 \%$ of women had their first antenatal care visit in the first trimester, and hence, most pregnant women missed anemia interventions.

Another finding is that more than half the women with anemia (57.1\%) had 10 or less antenatal care visits. In other words, the women who were admitted for antenatal care less than 10 times during the pregnancy had significantly higher prevalence of anemia than those that were admitted 10 times or more during the pregnancy. A multi-country randomized control trial conducted by WHO showed that essential interventions can be provided over four visits at specified intervals, at least for healthy women (18). Contrary to this report, our study showed that women with antenatal visit numbers between 5 and 10 were also associated with anemia before delivery. The reason for this relation may be explained by the fact that the women in our study could have underlying medical problems accompanying anemia, which increased the antenatal visit number. Moreover, it is possible that some hospital admissions resulted from reasons other than antenatal care such as prescription or maternal anxiety. Furthermore, a systematic review including a total of over 60,000 women compared the effects of reduced antenatal care visits (4-9 visits) with standard care (13-14 visits) (19). In that study, the reduced visit model was not associated with significant increases in postpartum anemia (Relative risk $=0.88,95 \% \mathrm{CI}=0.75-1.03$ ) (19). Similarly, we think that the impact of antenatal visit number on maternal anemia in our study mainly resulted from the gestational age at the initiation of antenatal care. An earlier gestational age at first admission will increase the total antenatal care visits at the end of pregnancy and will also prevent the depletion of iron stores because of early supplementation.

After multivariate logistic regression analysis, the association between anemia and preeclampsia still remained significant. It is already known that $10-20 \%$ of women with severe preeclampsia could progress to hemolysis, elevated liver enzymes, and low platelet syndrome, which is characterized by microangiopathic hemolytic anemia (20). On the other hand, maternal anemia and iron deficiency during the first trimester of pregnancy were demonstrated to cause subsequent development of preeclampsia through the stimulation of cortisol releasing hormone and alterations in the peripheral gas exchange of placental villi (21). 
Because of the retrospective design of this study, whether anemia preceded the preeclampsia or vice versa could not be verified. The limitation of our study was that we could not identify potential confounding variables such as folic acid deficiency because of the retrospective design of the study. Although we excluded some of the reasons of anemia including hemoglobinopathies and chronic inflammatory diseases, folic acid deficiency could not be assessed in the study as a causative factor for anemia during pregnancy. However, the prevalence of anemia in pregnancy secondary to folate deficiency was known to be approximately $3 \%$ (22). Hence, we thought that this incidence is too low to cause a significant alteration in the evaluation of our findings. Another limitation is the failure to identify the causes of anemia in pregnant women who received routine antenatal supplementation. Data in the medical records of women did not allow us to conclude about all etiologies of persistent anemia. The possible explanation why some pregnant women did not benefit from supplementation is that most of them could have been suffering from deleterious effects of undiagnosed medical disorders and were possibly anemic before pregnancy. Therefore, iron and folic acid supplementation is an important part of anemia control program, but supplements should be viewed as one of the several tools in the battle against anemia. In conclusion, our study provides evidence about the underlying factors for anemia among pregnant women attending our center for delivery at term. Based on the results of this study, identification of pregnant women with these factors is a worthy consideration for the reduction of anemia during and after delivery. We recommend that socioeconomic determinants, which cause limited access to adequate food and antenatal care, constitute most of the anemia cases and hence, should be recognized as major risk factors for anemia in women who are going to deliver. In many developing countries, pregnant women start antenatal care in the second or third trimester due to the belief that antenatal care is curative rather than protective. Therefore, those women should be encouraged to begin antenatal care early after conception to allow adequate time for restoring iron stores.

Ethics Committee Approval: Ethics committee approval was received for this study from the ethics committee of Tepecik Training and Research Hospital.

Informed Consent: Written informed consent was obtained from patients who participated in this study.

Peer-review: Externally peer-reviewed.

Author Contributions: Concept - C.E.T., A.E.; Design - C.E.T., A.E., U.S.; Supervision - C.E.T., M.Ö., C.G.; Resource - B.C.., M.K., M.B.E.; Materials - B.Ç., M.K., M.B.E.; Data Collection and/or Processing - B.Ç., M.K., M.B.E.; Analysis and/or Interpretation - A.E., U.S., C.G.; Literature Search - U.S., C.G.; Writing - C.E.T., A.E., C.G.; Critical Reviews - U.S., M.Ö.

Conflict of Interest: No conflict of interest was declared by the authors.

Financial Disclosure: The authors declared that this study has received no financial support.

\section{References}

1. Tolentino K, Friedman JF. An update on anemia in less developed countries. Am J Trop Med Hyg 2007; 77: 44-51.

2. Karaoglu L, Pehlivan E, Egri M, Deprem C, Gunes G, Genc MF, Temel I. The prevalence of nutritional anemia in pregnancy in an east Anatolian province, Turkey. BMC Public Health 2010; 10: 329. [CrossRef]

3. McLean E, Cogswell M, Egli I, Wojdyla D, de Benoist B. Worldwide prevalence of anaemia, WHO Vitamin and Mineral Nutrition Information System, 1993-2005. Public Health Nutr 2009; 12: 444-54. [CrossRef]

4. Levy A, Fraser D, Katz M, Mazor M, Sheiner E. Maternal anemia during pregnancy is an independent risk factor for lowbirthweight and prterm delivery. Eur J Obstet Gynecol Reprod Biol 2005; 122: 182-6.

5. Adebisi OY, Strayhorn G. Anemia in pregnancy and race in the United States: blacks at risk. Fam Med 2005; 35: 655-62. [CrossRef]

6. Ehrenthal DB, Chichester ML, Cole OS, Jiang X. Maternal risk factors for peripartum transfusion. J Womens Health (Larchmt) 2012; 21: 792-7. [CrossRef]

7. Jansen AJ, van Rhenen DJ, Steegers EA, Duvekot JJ. Postpartum hemorrhage and transfusion of blood and blood components. Obstet Gynecol Surv 2005; 60: 663-71. [CrossRef]

8. Rouse DJ, MacPherson C, Landon M, Varner MW, Leveno KJ, Moawad AH, et al. Blood transfusion and cesarean delivery. Obstet Gynecol 2006; 108: 891-7. [CrossRef]

9. Al-Zirqi I, Vangen S, Forsen L, Stray-Pedersen B. Prevalence and risk factors of severe obstetric haemorrhage. BJOG 2008; 115: 1265-72. [CrossRef]

10. Al JF. Grandmultiparity: a potential risk factor for adverse pregnancy outcomes. J Reprod Med 2012; 57: 53-7.

11. Barroso F, Allard S, Kahan BC, Connolly C, Smethurst H, Choo L, et al. Prevalence of maternal anaemia and its predictors: a multi-centre study. Eur J Obstet Gynecol Reprod Biol 2011; 159: 99-105. [CrossRef]

12. Ezugwu EC, Mbah BO, Chigbu CO, Onah HE. Anaemia in pregnancy: a public health problem in Enugu, southeast Nigeria. J Obstet Gynaecol 2013; 33: 451-4. [CrossRef]

13. Ndukwu GU, Dienye PO. Prevalence and socio-demographic factors associated with anaemia in pregnancy in a primary health centre in Rivers State, Nigeria. Afr J Prm Health Care Fam Med 2012; 4: 328. [CrossRef]

14. Virender PG, Yogesh B, Taneja DK, Renuka S. Prevalence of anemia amongst pregnant women and its socio-demographic associates in a rural area of Delhi. Indian Journal of Community Medicine 2002; $27: 157-60$.

15. Beard JL. Effectiveness and strategies of iron supplementation during pregnancy. Am J Clin Nutr 2000; 71: 1288S-94S.

16. Haider BA, Olofin I, Wang M, Spiegelman D, Ezzati M, Fawzi WW; Nutrition Impact Model Study Group (anaemia). Anaemia, prenatal iron use, and risk of adverse pregnancy outcomes: systematic review and meta-analysis. BMJ 2013; 346: f3443. [CrossRef]

17. Cogswell ME, Parvanta I, Ickes L, Yip R, Brittenham GM. Iron supplementation during pregnancy, anemia, and birth weight: a randomized controlled trial. Am J Clin Nutr 2003; 78: 773-81.

18. Villar J, Ba'aqeel H, Piaggio G, Lumbiganon P, Miguel Belizan J, Farnot U, et al. WHO Antenatal Care Trial Research Group. WHO antenatal care randomized trial for the evaluation of a new model of routine antenatal care. Lancet 2001; 357: 1551-64. [CrossRef]

19. Dowswell T, Carroli G, Duley L, Gates S, Gülmezoglu AM, KhanNeelofur D, et al. Alternative versus standard packages of antenatal care for low-risk pregnancy. Cochrane Database Syst Rev 2010; 10: CD000934. [CrossRef]

20. Haram K, Svendsen E, Abildgaard U. The HELLP syndrome: clinical issues and management. A Review. BMC Pregnancy Childbirth 2009; 9: 8. [CrossRef]

21. Kingdom JC, Kaufmann P. Oxygen and placental villous development: origins of fetal hypoxia. Placenta 1997; 18: 613-21. [CrossRef]

22. Kilbride J, Baker TG, Parapia L, Khoury SA. Iron status, serum folate and $\mathrm{B}(12)$ values in pregnancy and postpartum: report from a study from Jordan. Ann Saudi Med 2000; 20: 371-6. 